\title{
Annual Report on the External Quality Assessment Scheme for Urinalysis and Fecal Occult Blood Testing in Korea (2017)
}

Chang-Ho Jeon, A-Jin Lee, Sang-Gyung Kim, Hun-Seok Suh, and Young-Cheol Bae Department of Laboratory Medicine, School of Medicine, Catholic University of Daegu, Daegu, Korea

Corresponding author: Chang-Ho Jeon

Department of Laboratory Medicine, Daegu Catholic University Medical Center, School of Medicine, Catholic University of Daegu, 33 Duryugongwon-ro 17-gil, Namgu, Daegu 42472, Korea

Tel: $+82-53-650-4144$

Fax: +82-53-653-8672

E-mail: chjeon@cu.ac.kr

pISSN: 2384-2458

eISSN: 2288-7261
In 2017, external quality assessment trials for urinalysis and fecal occult blood (FOB) were performed with 1,544 participants. Urine chemistry tests were performed three times and urine sediment and FOB tests were evaluated 2 times. Urine chemistry tests consisted of $\mathrm{pH}$, protein, glucose, ketone, bilirubin, blood, urobilinogen, nitrite, leukocyte, and specific gravity analyses. The results of the urine chemistry and specific gravity tests showed accuracy rates $>95 \%$. The accuracy rate of urine sediments was low, especially for fat droplets and atypical uric acid crystals. In the FOB quality test, all reagents showed accuracy rates $>82 \%$, which suggested the persistent improvement of false-positive reactions. In the FOB quantitative test, discrepant results depending on the instrument used were observed. To compensate for the result differences caused by the amounts of stool samples, the results should be reported using another unit ( $\mu \mathrm{g} / \mathrm{g}$ of stool).

(J Lab Med Qual Assur 2018;40:128-135)

Key Words: Quality control, Urinalysis, Occult blood

\section{서론}

요경검학분과의 2017년도 외부정도관리사업은 새로운 전 산입력시스템이 안정화되어 결과분석 및 보고가 제대로 이루 어졌다. 요화학검사는 3 차 시행하였고 총 12 개의 관리물질을 사용하였다. 요침사검사는 2 회 시행하였으며 총 8 개의 사진 을 게시하여 판독하도록 하였다. 대변잠혈검사(faecal occult blood, FOB) 또한 2회 시행하였으며 총 6개의 관리물질을 사 용하였다. 요화학검사 및 $\mathrm{FOB}$ 신빙도조사에는 국내에서 제조 된 관리물질을 사용하였다.

2017년 신빙도조사 사업결과에서 요화학검사는 $98 \%$ 이상 의 정답률을 나타내었고 기기회사별로도 정답률에 큰 차이가
없었다. 그러나 Beckmann (Beckman Coulter Inc., Brea, $\mathrm{CA}, \mathrm{USA})$ 장비로 판독한 백혈구검사에서 낮은 정답률( $75 \%)$ 을 보였다. 요침사검사에서는 $67.8 \%-86.7 \%$ 의 정답률을 나 타내어 개선의 여지가 필요하였다. $\mathrm{FOB}$ 에서는 정답률이 $90 \%$ 이상으로 위양성률이 높았던 2015년 이후 정답률의 개선 이 지속되었다[1].

\section{재료 및 방법}

\section{1. 대상}

요경검학분과에서는 대한임상검사정도관리협회에 등록된 기관을 대상으로 2017년도 4월, 6월, 8월 3차에 걸쳐 정도관 
리물질을 발송하였다. 발송기관 수는 1,544 기관으로 16 년도 1,487 기관에 비하여 57 기관이 증가되었으며 평균 회신율을 $88.3 \%$ 였다.

\section{2. 재료}

요화학검사를 위한 관리물질은 1차(CU-17-01-04), 2차 (CU-17-05-08), 3차(CU-17-09-12) 검체 모두 국내에서 제조 한 액상관리물질 4종씩을 각 회원기관에 냉장 포장하여 발송 하였다. 이 중 1 차 및 3 차에는 본 협회 홈페이지에 게시한 요 침사 사진 8 매 등 모두 20 종의 검체를 우송 및 게시하여 정도 관리 신빙도조사를 시행하였다. 결과치의 입력은 본 협회에서 구축한 신빙도조사사업 홈페이지에서 직접 입력하는 방식을 사용하였다. $\mathrm{FOB}$ 를 위한 관리물질도 1차 및 2차 검체 모두 국 내에서 제조한 점액성 분말관리물질 3종(CS-17-01-06)을 각 회원기관에 냉장 포장하여 발송하였다.

\section{3. 정도관리물질의 허용치}

요화학 및 $\mathrm{FOB}$ 검사의 경우 분과위원회에서 실험한 참고치, 각 기관에서 회신한 결과의 일치도를 고려하였으며, 정성값은 최빈도치 \pm 1 단계, 정량값은 평균 \pm 2 standard deviation의 범 위를 허용범위로 설정하였다.

\section{결과}

\section{1. 요화학검사 9종의 신빙도조사 성적}

요화학검사 9 종 $(\mathrm{pH}$, protein, glucose, ketone, bilirubin, blood, urobilinogen, nitrite, leukocyte)의 신빙도조사 성적 은 Table 1에 요약하였다. Table 1은 1차, 2차 및 3차 신빙도
조사에서 얻어진 평균 정답률을 구한 자료이며, 모든 항목에서 $95 \%$ 이상의 정답률을 나타내었다.

\section{2. 요화학 분석기에 따른 요화학검사 신빙도조사 성적}

각 회사별 요화학 분석기에 따른 요화학검사의 신빙 도조사 성적은 Table 2와 같다. YD (YD Diagnostics, Yongin, Korea)가 $42.8 \%$ 로 가장 많이 사용하고 있으며 SD (Standard Diagnostics, Seoul, Korea) 20.2\%, Roche (Roche, Mannheim, Germany) 16.0\%, DFI (DFI Co. Ltd., Gimhae, Korea) 9.3\% 순이었다. 회사별 장비에 따라 요화 학검사의 정답률은 차이를 보이지 않았으나 Beckman 장비 (Beckman Coulter Inc., Brea, CA, USA)는 백혈구 검출에 서 $75 \%$ 의 낮은 정답률을 나타내었으며, 이는 백혈구 양성 검 체를 음성으로 판독한 데서 기인하였다.

Beckman 장비의 음성 판독은 2016년부터 지속되어 그 원 인을 분석하고자 하였다[2]. 대구가톨릭대학병원 진단검사 의학과에서는 환자들의 소변을 YD사의 Uriscan Super 장 비로 분석하여 백혈구 양성으로 나온 132예를 대상으로, Beckman사의 iChem Velocity 장비로 재검하였다. 124예에 서 1단계 이하의 일치를 보여 $93.9 \%$ 의 일치율을 나타내어, 환자 검체 분석에는 위음성 현상이 관찰되지 않았다. 이에 기 질효과(matrix effect)가 의심되어 정도관리물질을 한국고 분자 시험연구소(Seoul, Korea)에 의뢰하여 분석하였다. 분 석결과 2-methyl-p-anisidine (4-methoxy-o-toluidine) 및 n-methyl-p-anisidine이 백혈구 시약의 diazonium salt과 반 응하는 것으로 보고하였다. 즉 백혈구의 esterase 효소 대신 상기 두 가지 물질이 반응하여 양성 결과를 나타낸다고 하였 다. 이에 정도관리물질을 Beckman사와 $\mathrm{YD}$ 사의 요시험지봉

Table 1. Number of participants and acceptable rates of urine chemistry QC

\begin{tabular}{|c|c|c|c|c|c|c|}
\hline \multirow{2}{*}{ Tests } & \multicolumn{2}{|c|}{ 1st QC } & \multicolumn{2}{|c|}{ 2nd QC } & \multicolumn{2}{|c|}{ 3rd QC } \\
\hline & Participants & Acceptable (\%) & Participants & Acceptable (\%) & Participants & Acceptable (\%) \\
\hline $\mathrm{pH}$ & 1,312 & 95.1 & 1,310 & 97.3 & 1,450 & 98.2 \\
\hline Glucose & 1,312 & 98.8 & 1,310 & 97.4 & 1,451 & 98.1 \\
\hline Ketone & 1,282 & 99.8 & 1,281 & 99.6 & 1,415 & 99.6 \\
\hline Blood & 1,312 & 97.9 & 1,310 & 96.9 & 1,449 & 98.6 \\
\hline Urobilinogen & 1,282 & 99.6 & 1,281 & 98.3 & 1,415 & 99.6 \\
\hline Nitrite & 1,266 & 99.3 & 1,266 & 99.3 & 1,393 & 99.7 \\
\hline Leukocyte & 1,257 & 97.2 & 1,257 & 98.7 & 1,385 & 97.7 \\
\hline
\end{tabular}

Abbreviation: QC, quality control. 
Journal of LABORATORY MEDICINE and QUALITY ASSURANCE

Chang-Ho Jeon et al • External Quality Assessment in Urinalysis

Table 2. Acceptable rates according to urine analyzers from different companies

\begin{tabular}{lcccccccccc}
\hline Company & pH & Protein & Glucose & Ketone & Bilirubin & Blood & Urobilinogen & Nitrite & Leukocyte & Total \\
\hline YD & 97.6 & 98.4 & 98.6 & 97.9 & 99.8 & 98.6 & 99.7 & 99.6 & 97.4 & $545(42.8)$ \\
SD & 96.8 & 97.1 & 98.9 & 99.1 & 99.8 & 96.8 & 99.3 & 99.0 & 98.6 & $256(20.2)$ \\
Roche & 94.1 & 98.7 & 99.8 & 98.6 & 100.0 & 98.7 & 98.0 & 99.3 & 99.1 & $203(16.0)$ \\
DFI & 96.2 & 85.5 & 95.4 & 98.6 & 99.0 & 97.6 & 99.6 & 99.3 & 97.8 & $118(9.3)$ \\
Siemens & 99.9 & 99.7 & 99.2 & 99.8 & 96.6 & 98.7 & 98.4 & 99.8 & 99.2 & $80(6.3)$ \\
Eiken & 95.7 & 99.5 & 99.3 & 99.0 & 91.8 & 99.5 & 98.7 & 99.8 & 99.2 & $52(4.1)$ \\
Arkray & 100.0 & 98.6 & 100.0 & 100.0 & 100.0 & 98.0 & 99.5 & 99.7 & 100.0 & $31(2.5)$ \\
Symex & 100.0 & 98.5 & 100.0 & 98.0 & 97.9 & 100.0 & 98.9 & 100.0 & 92.6 & $14(1.1)$ \\
Beckman & 100.0 & 97.7 & 99.2 & 100.0 & 99.2 & 78.9 & 100.0 & 100.0 & 75.0 & $9(0.7)$ \\
\hline
\end{tabular}

Values are presented as \% or number (\%).

The instruments used were from the following companies: YD (YD Diagnostics, Yongin, Korea), SD (Standard Diagnostics, Seoul, Korea), Roche (Roche diagnostics, Mannheim, Germany), DFI (DFI Co. Ltd., Gimhae, Korea), Siemens (Siemens Healthcare (Erlangen, Germany), Eiken (Eiken Chemical Co., Tokyo, Japan), Arkray (Arkray Inc., Kyoto, Japan), and Beckman (Beckman Coulter Inc., Brea, CA, USA).

에 반응시킨 후 육안관찰을 시도하였다(Fig. 1A). 백혈구 시약 에서 Beckman사는 연한 살색으로 YD사는 연자주빛으로 발 색되었다. 백혈구에 의한 Beckman사의 요시험지봉 발색반응 은 Fig. $1 \mathrm{~B}$ 와 같이 자주빛으로 발색된다.

\section{3. 요화학 분석기로 시행한 요비중검사 신빙도조사 성적}

요비중검사는 굴절계 검사는 시행하지 않고 요화학 분석 장 기로 측정하였다. Table 3 에서와 같이 모든 검체에서 $95 \%$ 이 상의 정답률을 나타내었다. 그러나 결과입력 시 잘못된 값이 입력되는 경우가 발생하여 각 기관에서 결과입력 시 주의가 필 요하였다.

\section{4. 사진 검체를 이용한 요침사물 검사결과}

사진 검체를 사용하여 시행한 요침사물 신빙도조사의 평균 정답률은 $68.67 \%$ 에서 $99.3 \%$ 의 정답률을 보였다(Figs. 2, 3, Table 4). 지방구(CUI-17-02)를 전분입자나 백혈구로 판정하 였고, 비정형 요산결정(CUI-17-05)을 과립원주나 적혈구 원 주로 판정하였다. 또한 납양원주(CUI-17-07)를 초자원주로 판정하였고, 이행상피세포와 세뇨관상피세포(CUI-17-06)의 구별이 용이하지 않았다. 따라서 요침사물에 대한 판독은 각 기관의 지속적인 개선 노력이 필요하였다.

\section{5. $\mathrm{FOB}$ 시약에 따른 $\mathrm{FOB}$ 정성검사의 정답률 및 시약의 분}

\section{포}

$\mathrm{FOB}$ 시약에 따른 $\mathrm{FOB}$ 정성검사의 정답률은 Table 5 에 나 타내었다. 시약은 SD FOB rapid test (268기관), YD FOB test (121기관), Eiken homocatch light (Eiken Chemical
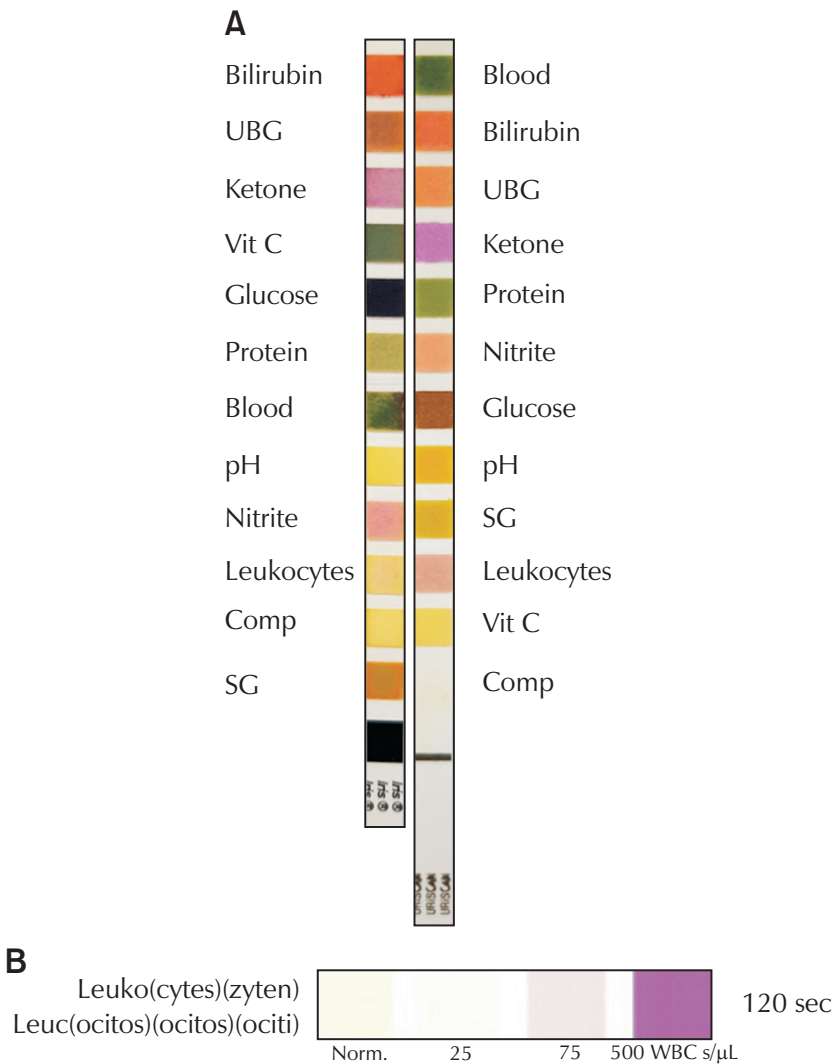

Fig. 1. (A) Gross examination of CU-17-04. Beckman (left) and YD (right) strips show results of urine chemistry reactions. At the leukocyte pads, the Beckman strip displays a slightly yellowish color, while the YD strip displays a pale purple color. (B) Color chart for leukocytes for the Beckman strip. Abbreviations: UBG, urobilinogen; Vit C, vitamin C; SG, specific gravity; WBC, white blood cell. 
Journal of LABORATORY MEDICINE and QUALITY ASSURANCE

Chang-Ho Jeon et al • External Quality Assessment in Urinalysis

Table 3. Acceptable rates of the urine specific gravity test

\begin{tabular}{lcccc}
\hline Specimen & Participants & Mean \pm standard deviation & 95\% Confidence interval & Acceptable (\%) \\
\hline CU-17-01 & 1,261 & $1.005 \pm 0.028$ & 1.001 to 1.010 & 97.5 \\
CU-17-02 & 1,261 & $1.009 \pm 0.004$ & 1.005 to 1.015 & 97.0 \\
CU-17-03 & 1,261 & $1.008 \pm 0.028$ & 1.005 to 1.018 & 95.6 \\
CU-17-04 & 1,261 & $1.021 \pm 0.006$ & 1.010 to 1.030 & 98.2 \\
CU-17-05 & 1,263 & $1.005 \pm 0.028$ & 1.001 to 1.015 & 94.9 \\
CU-17-06 & 1,262 & $1.008 \pm 0.004$ & 1.005 to 1.015 & 97.8 \\
CU-17-07 & 1,262 & $1.008 \pm 0.004$ & 1.005 to 1.015 & 96.3 \\
CU-17-08 & 1,262 & $1.019 \pm 0.040$ & 1.010 to 1.030 & 97.9 \\
CU-17-09 & 1,388 & $1.006 \pm 0.027$ & 1.001 to 1.015 & 96.8 \\
CU-17-10 & 1,388 & $1.007 \pm 0.027$ & 1.005 to 1.015 & 96.7 \\
CU-17-11 & 1,388 & $1.006 \pm 0.047$ & 1.005 to 1.015 & 95.6 \\
CU-17-12 & 1,388 & $1.018 \pm 0.054$ & 1.010 to 1.030 & 97.5 \\
\hline
\end{tabular}

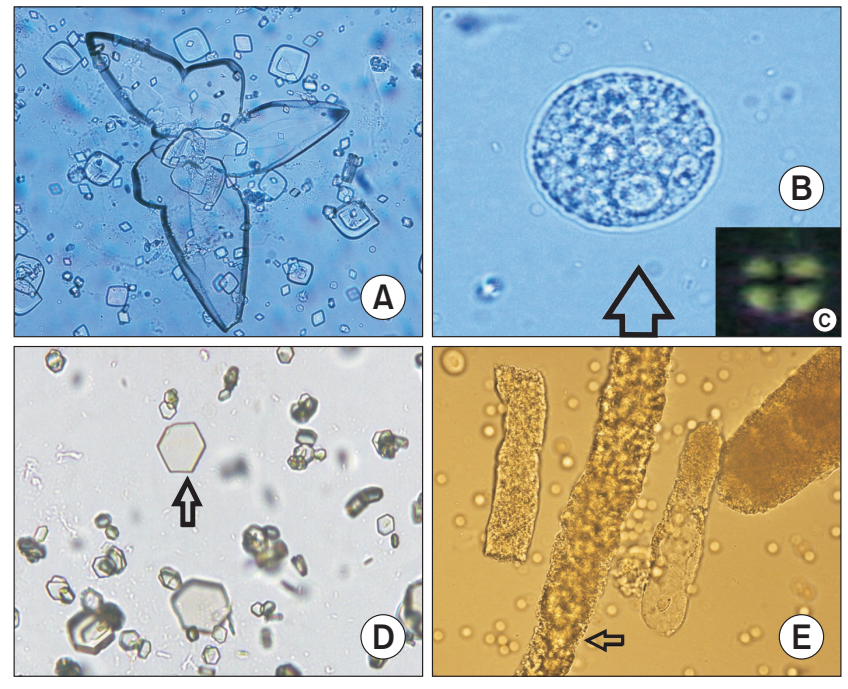

Fig. 2. Images of urine sediments (with arrow) for the external quality assessment. (A) CUI-17-01 uric acid crystal (original magnification $\times 400$ ). (B) CUI-17-02 fat globule (original magnification $\times 100)$. (C) Polarized microscopic images of panel B. (D) CUI-17-03 cystine crystal (original magnification $\times 400$ ). (E) CUI-17-04 cellular cast (original magnification $\times 400)$.

Co., Tokyo, Japan; 56기관), Asan FOB easy test (Asan Pharmaceutical, Seoul, Korea; 52기관) 순으로 사용하 였다. 모든 시약에서 양호한 정답률을 나타내었으나, $\mathrm{FOB}$ 음성 검체에서 $\mathrm{SD} F \mathrm{FOB}$, Humasis FOB test (Humasis Co., Anyang, Korea) 및 GC Genedia FOB (Green Cross Medial Science Co., Yongin, Korea) 시약에서 90\% 이하의

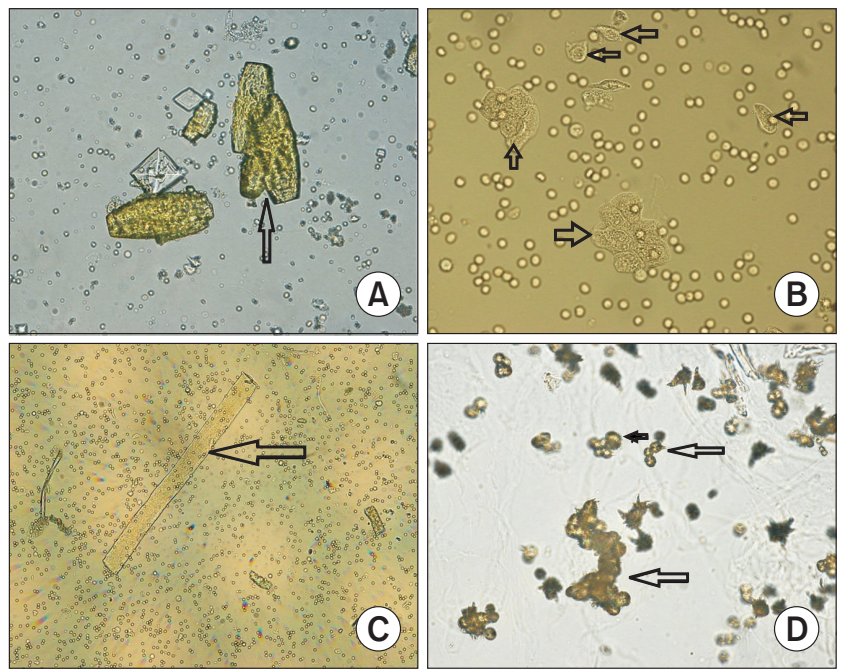

Fig. 3. Images of urine sediments (with arrow) for the external quality assessment. (A) CUI-17-05 uric acid crystal (original magnification $\times 200$ ). (B) CUI-17-06 renal tubular epithelial cell (original magnification $\times 400$ ). (C) CUI-17-07 waxy cast (original magnification $\times 100$ ). (D) CUI-17-08 ammonium urate crystal (original magnification $\times 400$ ).

낮은 정답률을 나타내었다. 특히 Humasis사 시약은 음성 검 체 2 개에서 모두 $90 \%$ 이하의 정답률을 나타내어 시약의 개선 이 필요하였다.

\section{6. $\mathrm{FOB}$ 시약에 따른 $\mathrm{FOB}$ 정량검사의 정답률 및 시약의 분 포}

$\mathrm{FOB}$ 정량검사결과 분포는 Table 6에 요약하였다. 장비별 
Journal of LABORATORY MEDICINE and QUALITY ASSURANCE

Chang-Ho Jeon et al • External Quality Assessment in Urinalysis

Table 4. Acceptable rates for the urine sediment examination

\begin{tabular}{|c|c|c|c|c|c|}
\hline Specimen no. & Results & Participants & Answers & Acceptable (\%) & Unacceptable (\%) \\
\hline CUI-17-01 & Uric acid & 752 & 747 & 99.3 & \\
\hline CUI-17-02 & Fat droplets & 752 & 516 & 68.6 & \\
\hline CUI-17-02 & Starch granule & 752 & 73 & & 9.7 \\
\hline CUI-17-02 & Leukocyte & 752 & 72 & & 9.6 \\
\hline CUI-17-03 & Cystine & 752 & 744 & 98.9 & \\
\hline CUI-17-04 & Granular cast coarsely & 752 & 523 & 69.5 & \\
\hline CUI-17-04 & $\mathrm{RBC} /$ pigmented/muddy brown casts & 752 & 123 & 16.4 & \\
\hline CUI-17-04 & Granular cast finely & 752 & 61 & 8.1 & \\
\hline CUI-17-04 & Cellular cast (RTE and/or neutrophil) & 752 & 17 & 2.3 & \\
\hline CUI-17-04 & Waxy cast & 752 & 14 & & 1.9 \\
\hline CUI-17-04 & Fatty cast & 752 & 12 & & 1.6 \\
\hline CUI-17-05 & Uric acid & 838 & 660 & 78.8 & \\
\hline CUI-17-05 & Granular cast coarsely & 838 & 40 & & 4.8 \\
\hline CUI-17-05 & $\mathrm{RBC/pigmented/muddy} \mathrm{brown} \mathrm{casts}$ & 838 & 40 & & 4.8 \\
\hline CUI-17-05 & Fiber/fecal contamination & 838 & 25 & & 3.0 \\
\hline CUI-17-05 & Calcium oxalate & 838 & 19 & & 2.3 \\
\hline CUI-17-05 & Fatty cast & 838 & 13 & & 1.6 \\
\hline CUI-17-06 & Transitional epithelial cell & 838 & 468 & 55.8 & \\
\hline CUI-17-06 & Renal tubular epithelial cell & 838 & 336 & 40.1 & \\
\hline CUI-17-06 & Squamous epithelial cell & 838 & 17 & & 2.0 \\
\hline CUI-17-07 & Waxy cast & 838 & 603 & 72.0 & \\
\hline CUI-17-07 & Fiber/fecal contamination & 838 & 105 & 12.5 & \\
\hline CUI-17-07 & Hyaline cast & 838 & 73 & & 8.7 \\
\hline CUI-17-07 & Granular cast finely & 838 & 27 & & 3.2 \\
\hline CUI-17-07 & Cholesterol & 838 & 19 & & 2.3 \\
\hline CUI-17-08 & Ammonium biurate & 838 & 796 & 95.0 & \\
\hline CUI-17-08 & Amorphous urates/phosphates & 838 & 23 & & 2.7 \\
\hline CUI-17-08 & Leucine & 838 & 14 & & 1.7 \\
\hline
\end{tabular}

로 검사에 사용하는 대변 양이 달라서 장비 간 비교가 어려워 이를 보정한 값을 함께 비교하였다. 사용장비는 Eiken (158기 관), Alfresa (Alfresa Pharma Co., Osaka, Japan; 60기관), Kyowa (Kyowa Chemical Industry Co., Kagawa, Japan; 35 기관) 순으로 분포하였다. 전체 평균에 비하여 Alfresa 장비 는 CS-17-01 및 CS-17-05 검체에서 높은 수치를 보였다. 또 한 Alfresa 장비는 CS-17-02, 17-03, 17-04 및 17-06 검체에 서 모두 낮은 농도를 나타내었다.

\section{고찰}

2017년의 정도관리 신빙도조사에서 나타난 특징은 참여기
관의 증가이다. 특히 3 차 신빙도조사에서는 1,450 기관이 참가 하여 1 차에 비하여 $10.7 \%$ 의 증가를 보였다. 결과를 분석해 볼 때 2016년 정도관리 신빙도사업결과와 매우 유사한 성적을 나 타내었다[2]. 백혈구를 제외한 요화학검사 및 비중검사는 우 수한 정답률을 유지하였다. 요침사 신빙도조사에서도 2016년 정답률 $67.8 \%-86.7 \%$ 보다 조금 상향된 성적을 보였다. $\mathrm{FOB}$ 정성검사에서는 2016년과 유사하게 음성 검체에 대한 위양성 률이 높지 않아 국내 시약의 질 개선이 이루어진 것으로 보인 다.

요화학검사에서는 2016년과 동일하게 Beckman 장비에서 leukocytes 양성인 검체를 음성으로 판독하였다. 이에 소변, 대변검사 위원회와 Beckman사가 공동으로 원인분석을 시행 
Journal of LABORATORY MEDICINE and QUALITY ASSURANCE

Chang-Ho Jeon et al • External Quality Assessment in Urinalysis

Table 5. Acceptable rates for the fecal occult blood quality test

\begin{tabular}{lccccccc}
\hline \multirow{2}{*}{ Reagents } & No. & CS-16-01 & CS-16-02 & CS-16-03 & CS-16-04 & CS-16-05 & CS-16-06 \\
\cline { 3 - 7 } & & Negative (\%) & Positive (\%) & Positive (\%) & Positive (\%) & Negative (\%) & Positive (\%) \\
\hline SD FOB rapid test & 268 & 92.9 & 99.6 & 100.0 & 100.0 & 86.2 & 100.0 \\
YD Occult Tech FOB test & 121 & 94.4 & 100.0 & 100.0 & 100.0 & 90.1 & 99.2 \\
Eiken Hemocatch light & 56 & 100.0 & 100.0 & 98.2 & 100.0 & 100.0 & 100.0 \\
ASAN easy test FOB & 52 & 92.7 & 100.0 & 100.0 & 100.0 & 96.2 & 98.1 \\
Humasis FOB test & 39 & 84.6 & 100.0 & 100.0 & 100.0 & 82.1 & 100.0 \\
Bio focus FOB rapid test & 30 & 93.3 & 100.0 & 100.0 & 100.0 & 93.3 & 100.0 \\
HBI HiSens FOB NCard & 26 & 96.7 & 96.7 & 96.7 & 100.0 & 96.2 & 100.0 \\
GC Genedia FOB & 18 & 94.1 & 94.1 & 100.0 & 100.0 & 88.9 & 100.0 \\
\hline
\end{tabular}

Abbreviation: FOB, fecal occult blood.

The instruments used were from the following companies: SD (Standard Diagnostics, Seoul, Korea), YD (YD Diagnostics, Yongin, Korea), Eiken Chemical Co. (Tokyo, Japan), Asan Pharmaceutical (Seoul, Korea), Humasis Co. (Anyang, Korea), Bio Focus Co. (Uiwang, Korea), HBI Co. (Anyang, Korea), and GC (Green Cross Medial Science Co., Yongin, Korea).

Table 6. Distribution of results of the fecal occult blood quantitation test

\begin{tabular}{|c|c|c|c|c|c|c|c|c|c|c|}
\hline \multirow{2}{*}{ Instruments } & \multirow{2}{*}{ Specimen } & \multirow{2}{*}{ No. } & \multicolumn{2}{|c|}{ Median } & \multicolumn{2}{|c|}{ Minimum } & \multicolumn{2}{|c|}{ Maximum } & \multicolumn{2}{|c|}{ Average } \\
\hline & & & $\mathrm{ng} / \mathrm{mL}$ & $\mu \mathrm{g} / \mathrm{g}$ stool & $\mathrm{ng} / \mathrm{mL}$ & $\mu \mathrm{g} / \mathrm{g}$ stool & $\mathrm{ng} / \mathrm{mL}$ & $\mu \mathrm{g} / \mathrm{g}$ stool & $\mathrm{ng} / \mathrm{mL}$ & $\mu \mathrm{g} / \mathrm{g}$ stool \\
\hline Eiken & CS-17-01 & 157 & 4.0 & 0.8 & 0.0 & 0.0 & 24.0 & 4.8 & 4.8 & 1.0 \\
\hline Alfresa & CS-17-01 & 58 & 56.0 & 10.6 & 3.0 & 0.6 & 149.0 & 28.3 & 53.7 & 10.2 \\
\hline Kyowa & CS-17-01 & 33 & 1.0 & 1.0 & 0.0 & 0.0 & 55.0 & 55.0 & 2.5 & 2.5 \\
\hline Eiken & CS-17-02 & 157 & 195.0 & 39.0 & 82.0 & 16.4 & 342.0 & 68.4 & 195.4 & 39.1 \\
\hline Alfresa & CS-17-02 & 58 & 151.0 & 28.7 & 53.0 & 10.1 & 213.0 & 40.5 & 150.4 & 28.6 \\
\hline Kyowa & CS-17-02 & 33 & 48.0 & 48.0 & 0.0 & 0.0 & 96.0 & 96.0 & 48.6 & 48.6 \\
\hline Eiken & CS-17-03 & 157 & 390.0 & 78.0 & 65.0 & 13.0 & 561.0 & 112.2 & 379.9 & 76.0 \\
\hline Alfresa & CS-17-03 & 58 & 264.5 & 50.3 & 58.0 & 11.0 & 370.0 & 70.3 & 259.7 & 49.3 \\
\hline Kyowa & CS-17-03 & 33 & 107.0 & 107.0 & 68.0 & 68.0 & 165.0 & 165.0 & 103.9 & 103.9 \\
\hline Eiken & CS-17-04 & 158 & 465.5 & 93.1 & 54.0 & 10.8 & 620.0 & 124.0 & 450.4 & 90.1 \\
\hline Alfresa & CS-17-04 & 60 & 302.0 & 57.4 & 51.0 & 9.7 & 400.0 & 76.0 & 295.7 & 56.2 \\
\hline Kyowa & CS-17-04 & 35 & 133.0 & 133.0 & 75.0 & 75.0 & 181.0 & 181.0 & 127.1 & 127.1 \\
\hline Eiken & CS-17-05 & 158 & 4.0 & 0.8 & 0.0 & 0.0 & 18.0 & 3.6 & 4.0 & 0.8 \\
\hline Alfresa & CS-17-05 & 60 & 46.0 & 8.7 & 1.0 & 0.2 & 122.0 & 23.2 & 54.5 & 10.4 \\
\hline Kyowa & CS-17-05 & 35 & 1.0 & 1.0 & 0.0 & 0.0 & 7.0 & 7.0 & 1.1 & 1.1 \\
\hline Eiken & CS-17-06 & 158 & 232.0 & 46.4 & 107.0 & 21.4 & 420.0 & 84.0 & 226.0 & 45.2 \\
\hline Alfresa & CS-17-06 & 60 & 179.0 & 34.0 & 111.0 & 21.1 & 325.0 & 61.8 & 180.5 & 34.3 \\
\hline Kyowa & CS-17-06 & 35 & 57.0 & 57.0 & 22.0 & 22.0 & 73.0 & 73.0 & 53.6 & 53.6 \\
\hline
\end{tabular}

The instruments used were from the following companies: Eiken Chemical Co. (Tokyo, Japan), Alfresa Pharma Co. (Osaka, Japan), and Kyowa Chemical Industry Co. (Kagawa, Japan).

하였다. Beckman사 장비는 실제 환자들의 소변 검체에서는 위음성을 보이지 않았으나, 정도관리 검체에서는 위음성을 보 여 기질효과를 의심하였다. 한국고분자 시험연구소에서 정도 관리물질 분석을 의뢰한 결과 백혈구 시약반응에 양성을 일으
킬 수 있는 2가지 물질을 발견하였다. Beckman사 시약과 YD 사 시약을 대상으로 정도관리물질을 반응시켜 육안 판독한 결 과, Beckman사 시약에서는 발색반응이 비특이적으로 일어났 다. 즉 백혈구의 esterase과 반응하여 발색되는 자색반응이 아 


\title{
Journal of LABORATORY MEDICINE and QUALITY ASSURANCE
}

\author{
Chang-Ho Jeon et al • External Quality Assessment in Urinalysis
}

니라 살색반응이 나타나서 장비에서 잘 검출하지 못하는 것으 로 판단되었다. 따라서 Beckman사 장비로 신빙도조사를 시 행할 경우 장비판독과 육안판독을 모두 시행하여, 비특이적인 발색반응으로 인한 위음성 반응이 의심되는 경우, 육안판독 결 과를 보고하는 것이 바람직할 것이다.

요비중검사는 참여기관의 정답률이 양호한데, 드물게 결과 입력오류가 발견되었다. 0, 0.01, 0.02 등 비정상적인 결과가 입력되는데, 입력방법을 잘 숙지하여 입력오류에 의한 불합격 판정을 받지 않아야겠다.

요침사 신빙도조사에서는 지방구, 비정형 요산결정 등에서 낮은 정답률을 기록하였다. 두 가지 침사 모두 빈번하게 나타 나는 형태는 아니지만 각각 신증후군과[3] 요산결석을[4] 시 사할 수 있다. 정답으로 평가하였지만 세뇨관 상피세포와 이행 상피세포의 감별은 아직도 잘 이루어지지 못하고 있다. 요침사 물을 정확하게 판독하려면 판독경험이 많아야 하므로 각 병원 에서 요침사 판독전문가를 1 명 이상 육성하는 것이 바람직할 것이다.

$\mathrm{FOB}$ 정성검사에서 2015년 전 시약에서 음성 검체를 양성 으로 판독하여 오답률이 $89.0 \%$ 에 달하여 문제점으로 부각되 었다. 정성시약의 과도한 민감도를 낮추기 위하여 국내 $\mathrm{FOB}$ 시약회사들에게 민감도 조정을 요청하였고, 2016년에 2회에 걸쳐 $\mathrm{FOB}$ 음성인 검체로 신빙도조사사업을 시행한 결과 모 두 90\% 이상의 정답률을 보였다. 2017년에도 FOB 음성인 검 체에서 $84.6 \%$ 이상의 정답률을 보여 다소 정답률이 하락하 였으나, 위양성 문제는 해결된 것으로 보였다. 본 위원회에서 는 시판되는 6개 시약(SD, YD, Eiken, Asan, Humasis 및 BioFocus)을 대상으로 2017년 11월 민감도 개선 여부를 확인 하였으며, $20 \mathrm{ng} / \mathrm{mL}$ 이하의 환자 대변 검체에서 평균 양성률 $6.4 \%$ 를 나타내었다(data not shown). 이 결과에 대한 세부내 용은 논문으로 출판할 것이다.

대변잠혈 정량검사에서 Alfresa는 2016년과 동일하게 저농 도 검체에서는 높게, 중등 및 고농도 검체에서는 낮게 측정하 였다. Kyowa 장비는 중등 및 고농도 검체에서 다소 높게 측 정되었다. $\mathrm{FOB}$ 는 장비에 따라 결과 차이를 보일 수 있으며 [5], 특히 측정 시 주입되는 대변 양이 달라서 $\mathrm{ng} / \mathrm{mL}$ 의 단위
로 보고하면 농도차이를 보일 수 있다. 이를 보완하기 위하여 $\mathrm{FOB}$ 의 또 다른 보고단위인 $\mu \mathrm{g} / \mathrm{g}$ stool을 도입하여 병행 사용 을 추진하였으나[6], 참가기관에서 주입하는 대변 양을 정확 하게 측정하기 어려워 2017년 신빙도조사사업에서 시행하지 못하였다. Table 6 에 제시된 $\mu \mathrm{g} / \mathrm{g}$ stool에 의한 수치는 실제치 가 아니고 장비별로 주입되는 대변 양을 일괄적으로 적용하여 산출된 수치이므로 정확하지 않다. 따라서 장비별로 발생하는 $\mathrm{FOB}$ 결과차이에 대한 원인을 분석하기는 어려우며, 사용하 는 기관에서 장비별 특성을 잘 고려하여 참고치를 산정해야 할 것이다.

\section{REFERENCES}

1. Jeon $\mathrm{CH}$, Lee AJ; Urinalysis and Routine Microscopy Subcommittee, Korean Association of External Quality Assessment Service. Annual report on the external quality assessment scheme for urinalysis and faecal occult blood testing in Korea (2015). J Lab Med Qual Assur 2016;38:120-8.

2. Jeon CH, Lee AJ, Kim SG, Suh HS, Bae YC. Annual report on the external quality assessment scheme for urinalysis and faecal occult blood testing in Korea (2016). J Lab Med Qual Assur 2017;39:117-23.

3. McPherson RA, Pincus MR. Henry's clinical diagnosis and management by laboratory methods. 23rd ed. St. Louis (MO): Elsevier, 2017.

4. Cicerello E. Uric acid nephrolithiasis: an update. Urologia 2018;85:93-8.

5. Kim JH, Hwang SY, Kim YJ. Evaluation of Hemo Techt NS-plus C15 Automatic Analyzer for fecal occult blood test. J Lab Med Qual Assur 2010;32:237-41.

6. Sinatra MA, Young GP, St John DJ, Blake D, Ratnaike S. A study of laboratory based faecal occult blood testing in Melbourne, Australia. The Faecal Occult Blood Testing Study Group. J Gastroenterol Hepatol 1998;13:396-400. 
Journal of LABORATORY MEDICINE and QUALITY ASSURANCE

Chang-Ho Jeon et al • External Quality Assessment in Urinalysis

요 및 대변잠혈검사 신빙도조사 결과보고(2017)

전창호・이아진・김상경 • 서헌석・배영철

대구가톨릭대학교 의과대학 진단검사의학교실

2017년 요경검 및 대변잠혈검사ffaecal occult blood, FOB) 정도관리사업이 1,544개 기관이 참여하 여 시행되었다. 요화학검사는 3회에 걸쳐 시행되었고, 사진판독에 의한 요침사물 판정 및 FOB검사 는 2회 실시하였다. 요화학검사는 pH, protein, glucose, ketone, bilirubin, blood, urobilinogen, nitrite, leukocyte 및 specific gravity (SG) 등 10항목이었다. 요화학검사 및 요시험지봉에 의한 SG검사는 95\% 이상의 우수한 정답률을 나타내었으나, 요침사물검사는 지방구 및 비정형 요산결정에서 낮은 정답율을 보였다. FOB 정성 검사에서 82\% 이상의 정답률을 보여 정답률이 2016년에 비하여 다소

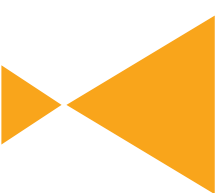

Journal of

LABORATORY MEDICINE and

QUALITY ASSURANCE 하락하였으나, 위양성 문제는 개선되었다. $\mathrm{FOB}$ 정량검사는 장비 간에 농도차이를 보였으며, 대변 양 사용에 따른 농도차이를 보완하기 위하여 $u g / g$ stool로 보고할 필요가 지속적으로 제기되고 있 다.

(J Lab Med Qual Assur 2018;40:128-135) 